\title{
Different sucrose-isomaltase response of Caco-2 cells to glucose and maltose suggests dietary maltose sensing
}

\author{
Min-Wen Cheng, ${ }^{1,2}$ Mohammad Chegeni, ${ }^{1,2}$ Kee-Hong Kim, ${ }^{2}$ Genyi Zhang, ${ }^{3}$ Mustapha Benmoussa, ${ }^{3}$ \\ Roberto Quezada-Calvillo, ${ }^{4,5}$ Buford L. Nichols ${ }^{4}$ and Bruce R. Hamaker ${ }^{1,2, *}$

\begin{abstract}
'Whistler Center for Carbohydrate Research, 745 Agriculture Mall Drive and ${ }^{2}$ Department of Food Science, Purdue University, West Lafayette, IN 47907-2009, USA

${ }^{3}$ School of Food Science and Technology, Jiangnan University, 1800 Lihu Avenue, Wuxi, Jiangsu 214122, P.R. China

${ }^{4}$ USDA/ARS Children's Nutrition Research Center and the Department of Pediatrics, Baylor College of Medicine, Houston, TX 77030, USA

${ }^{5}$ Department of Chemistry, Universidad Autonoma de San Luis Potosi, San Luis Potosi 78210, Mexico
\end{abstract}

(Received 10 July, 2013; Accepted 22 October, 2013; Published online 20 December, 2013)

\begin{abstract}
Using the small intestine enterocyte Caco-2 cell model, sucraseisomaltase (SI, the mucosal $\alpha$-glucosidase complex) expression and modification were examined relative to exposure to different mono- and disaccharide glycemic carbohydrates. Caco-2/TC7 cells were grown on porous supports to post-confluence for complete differentiation, and dietary carbohydrate molecules of glucose, sucrose (disaccharide of glucose and fructose), maltose (disaccharide of two glucoses $\alpha-1,4$ linked), and isomaltose (disaccharide of two glucoses $\alpha-1,6$ linked) were used to treat the cells. qRT-PCR results showed that all the carbohydrate molecules induced the expression of the SI gene, though maltose (and isomaltose) showed an incremental increase in mRNA levels over time that glucose did not. Western blot analysis of the SI protein revealed that only maltose treatment induced a higher molecular weight band (Mw $\sim 245 \mathrm{kDa}$ ), also at higher expression level, suggesting post-translational processing of $\mathrm{SI}$, and more importantly a sensing of maltose. Further work is warranted regarding this putative sensing response as a potential control point for starch digestion and glucose generation in the small intestine.
\end{abstract}

Key Words: maltose, mucosal $\alpha$-glucosidases, small intestine, sensing, sucrase-isomaltase

$\mathrm{C}$ hronic consumption of high glycemic foods and the accompanying quick high blood glucose response after food consumption is thought to be unhealthy, because it increases oxidative stress in cells and stresses the incretin system responsible for controlling blood sugar levels. ${ }^{(1)}$ This increase in stress may correlate to Type 2 diabetes and coronary heart disease, and has been implicated as a factor in the development of obesity. ${ }^{(2)}$ Glycemic carbohydrate absorption occurs in the form of the monosaccharides glucose, fructose, and galactose; through digestion at the small intestine mucosal enterocyte level of maltooligosaccharide products of $\alpha$-amylase hydrolysis of starch and the disaccharides of sucrose and lactose. Maltose is one of the major starch degradation products of $\alpha$-amylase. Starches are digested at different rates in the human small intestine, mainly depending on food form; enterocytes in the more distal parts may not require constant luminal-surface presence of the $\alpha$-glucosidases for their conversion to glucose. The ability of small intestinal enterocytes to sense maltooligosaccharides for the purpose of digestion has not been established.

Digestion of starch in the human involves the function of several enzymes. Salivary and pancreatic $\alpha$-amylases are secreted, respectively, to initiate and degrade starch to maltooligosaccharides. ${ }^{(3)}$ Pancreatic $\alpha$-amylase plays a more dominant role in starch digestion than salivary amylase. ${ }^{(4)} \alpha$-Amylase is an endo-enzyme (or endo-glucosidase) that hydrolyzes the internal $\alpha-1,4$ glycosidic linkages of amylose and amylopectin to form short linear (i.e., maltose, maltotriose, maltotetraose) and branched dextrin chains ( $\alpha$-limit dextrins). ${ }^{(5)}$ These maltooligosaccharide products are further digested to glucose by the mucosal $\alpha$-glycosidases, sucrase-isomaltase (SI) and maltase-glucoamylase (MGAM). ${ }^{(6)}$ All four catalytic subunits of SI and MGAM are capable of hydrolyzing $\alpha-1,4$ linkages, while the isomaltase subunit has the capacity to hydrolyze the $\alpha-1,6$ linkage. ${ }^{(7)}$ Mammalian small intestines have more abundant SI than MGAM, ${ }^{(8)}$ although the latter has higher enzyme activity. ${ }^{(9-11)}$ The human Caco-2 cell line synthesizes only SI; though, because it contains the full complement of $\alpha$-glucogenic activities, it is still considered a good model to study aspects of starch digestion.

Delivery of monosaccharides to the body depends on the expression of the monosaccharide transporters. After carbohydrate digestion to monosaccharides, glucose and galactose are transported into small intestinal enterocytes through the sodiumdependent glucose transporter (SGLT1); and fructose is transported into enterocytes by the facilitated glucose transporter type 5 (GLUT5). These monosaccharides are transported from enterocytes into the circulation system through the facilitated glucose transporter type 2 (GLUT2). ${ }^{(12)}$ GLUT2 also migrates to the apical surface to assist in fructose and glucose absorption when high sugar concentration is present. ${ }^{(13)}$ Understanding the coordination between the expression of the digestive enzymes and expression of the different types of transporters may provide another clue as to the control of glycemic response. Kishi ${ }^{(14)}$ showed in rats that fructose increased mRNA expression of SI which is one of the major $\alpha$-glycosidases for hydrolysis of sucrose, and as well increased mRNA expression of SGLT1, GLUT5, and GLUT2. Thus, there may be coordination at the transcriptional level of both the digestion enzymes and glucose transporters. On the other hand, post-translational processing of SI involving different glycosylation steps adds another layer of complexity to regulation of the active form of the enzyme. Also, there are a number of types of carbohydrates that are exposed to the small intestinal enterocytes during the digestion and absorption processes. Le Gall et al. ${ }^{(15)}$ demonstrated that sugar (sucrose) sensing by the enterocytes is a complex process which combines the sensing of sugar, the sensing of sugar metabolites, and where the sensing receptors are located

To whom correspondence should be addressed.

E-mail: hamakerb@purdue.edu 
on the membrane.

Caco-2 cells are cells derived from human colonic adenocarcinoma cells. These cells are commonly used in in vitro models to study intestinal absorption of compounds. This cell line undergoes spontaneous differentiation and forms a monolayer after long-term culture and displays several biochemical and morphological characteristics of mature small intestinal enterocytes after the differentiation. ${ }^{(16)}$ Several clones have been isolated from the Caco-2 cell line and characterized for their activities. Among them, the Caco-2/TC7 clone was isolated from a late passage of the parental Caco-2 line and consists of a more homogeneous population with better representative functions of the small intestinal enterocytes, and with more developed intercellular junctions. ${ }^{(17)}$ Because it is known that Caco-2/TC7 cells express numerous transporters such as SGLT1, GLUT1, GLUT2, GLUT3, GLUT5, and CAT1, this cell line is used as a model of the absorptive properties of the intestinal mucosa. ${ }^{(18)}$

In this study, the sucrase-isomaltase and transporter transcription and translation response of human enterocyte Caco-2/TC7 cells to some commonly encountered simple glycemic carbohydrate structures was investigated. The focus was on whether the cells are able to sense the starch degradation disaccharide (maltose) that it is required to digest to glucose for absorption.

\section{Materials and Methods}

Caco- 2 cell culture. The Caco- $2 / \mathrm{TC} 7$ clone at passage of 82-93 was selected for this study. Cells were seeded as $1.5 \times 10^{3}$ cells/well on 96-well solid supports (Becton Dickinson, Franklin Lakes, NJ), $6.4 \times 10^{4}$ cells/well on 6-well solid support (Corning, Lowell, MA), or $1.25 \times 10^{5}$ cells/well on 6 -well porous $(0.4 \mu \mathrm{m}$ polycarbonate membrane) transwell supports (Corning, Lowell, MA). Cells were grown in Dulbecco's modified Eagle's medium ( $25 \mathrm{mM}$, or equal to $4.5 \mathrm{~g} / \mathrm{l}$ glucose DMEM, Lonza BioWhittaker, Walkersville, MD) supplied with $10 \%$ heat-inactivated $\left(56^{\circ} \mathrm{C}\right.$, $30 \mathrm{~min}$ ) fetal bovine serum (FBS) (Lonza, Walkersville, MD), $50 \mu \mathrm{g} / \mathrm{ml}$ gentamycin sulfate (J R Scientific Inc., Woodland, CA), $10 \mathrm{mM}$ HEPES, $100 \mu \mathrm{g} / \mathrm{ml}$ streptomycin and $100 \mathrm{U} / \mathrm{ml}$ penicillin (Lonza, Walkersville, MD), and $100 \mu \mathrm{M}$ non-essential amino acid (Lonza BioWhittaker, Walkersville, MD). Cells were incubated at $37^{\circ} \mathrm{C}$ with $5 \% \mathrm{CO}_{2}, 95 \%$ air atmosphere, and at constant humidity. Because Caco-2/TC7 cells express higher levels of SI, SGLT1, GLUT2, and GLUT5 in the stationary phase of growth, ${ }^{(19)}$ cells required longer time culture. Media were renewed every $48 \mathrm{~h}$ until 10 days post-confluence for the complete differentiation of the cells. ${ }^{(15)}$ Cell viability was measured by the MTS [3-(4,5dimethylthiazol-2-yl)-5-(3-carboxymethoxyphenyl)-2-(4-sulfophenyl)-2H-tetrazolium] assay. ${ }^{(20)}$

Sugar digestion and transportation. Cells on transwells were washed twice with $1 \mathrm{ml}$ PBS after they reached $100 \%$ confluence and were fully differentiated. Cells were then fed with glucose-free DMEM (Gibco, Carlsbad, CA) in the basolateral well region. Test carbohydrates of glucose and maltose were supplied to the glucose-free DMEM (Gibco, Carlsbad, CA). The different media were supplied to the apical part of the transwell. The amount of glucose in the media in apical and basolateral regions was measured at different incubation times using the glucose oxidase/peroxidase assay kit (GOPOD, Megazyme, Bray, Ireland).

Total RNA isolation. Total RNA of cells was stabilized by storing in RNAlater solution (Ambion, Austin, TX) at $4{ }^{\circ} \mathrm{C}$ for overnight. Equipment used for RNA extraction was soaked in DEPC- $\mathrm{H}_{2} \mathrm{O}$ (diethyl dicarbonate, $0.1 \% \mathrm{v} / \mathrm{v}$; Sigma, St Louis, MO) for at least $1 \mathrm{~h}$ at $37^{\circ} \mathrm{C}$ followed by autoclaving at $121^{\circ} \mathrm{C}$ for 30 min to inactivate RNases. Total RNA was extracted using the SV Total RNA Isolation System (Promega, Madison, WI) according to manufacturer's protocol. RNA samples were diluted and measured at 260 and $280 \mathrm{~nm}$. RNA concentration was calculated by A260 according to the Beer-Lambert law and RNA purity was determined by the ratio of A260/A280. High purity of RNA should give an A260/A280 ratio value higher than 1.8.

CDNA synthesis and real-time PCR analysis. Relative levels of SI and SGLT1, GLUT5, and GLUT2 transporter mRNA expressed in the treated Caco-2 cells were quantified over a $48 \mathrm{~h}$ period by reverse transcription and qRT-PCR. Oligo dT $(500 \mu \mathrm{g} /$ $\mathrm{ml}$, Promega, Madison, WI) was used as primers for first-strand cDNA synthesis of total RNA. Reverse transcription polymerase chain reaction (qRT-PCR) was performed using two systems. Some samples were reverse transcripted by using the Access qRTPCR System (Promega, Madison, WI) according to manufacturer's instructions. Each qRT-PCR $(20 \mu \mathrm{l})$ of other samples was performed by heating a mixture $(1 \mu \mathrm{l}$ of Oligo $\mathrm{dT}, 1-2 \mu \mathrm{g}$ of total RNA, $1 \mu \mathrm{l}$ of $10 \mathrm{mM}$ dNTP mix, Invitrogen, Carlsbad, CA, and $16 \mu \mathrm{l}$ of DEPC- $\mathrm{H}_{2} \mathrm{O}$ ) at $65^{\circ} \mathrm{C}$ for $5 \mathrm{~min}$ and then adding M-MuLV Reverse Transcriptase Reaction Buffer (BioLabs, Ipswich, MA) and 25 units of M-Mulv reverse transcriptase (BioLabs, Ipswich, MA) to react at $42^{\circ} \mathrm{C}$ for $1 \mathrm{~h}$. The reaction was inactivated by heating at $95^{\circ} \mathrm{C}$ for $5 \mathrm{~min}$.

qRT-PCR analysis was performed by using the MX3000P QPCR system (Stratagene, La Jolla, CA) in the presence of SYBR-green. The primers used were:

- SGLT1 forward primer (5'-TGGCAATCACTGCCCTTTA-3') and SGLT1 reverse primer (5'-TGCAAGGTGTCCGTGTAAAT$\left.3^{\prime}\right){ }^{(15)}$

- GLUT2 forward primer (5'-GTCCAGAAAGCCCCAGATACC-3') and reverse primer (5'-GTGACATCCTCAGTTCCTCTTAG-3'), ${ }^{(21)}$

- GLUT5 forward primer (5'-TCTCCTTGCAAACGTAGATGG-3') and reverse primer (5'-GAAGAAGGGCAGCAGAAGG-3'), ${ }^{(15)}$

- SI forward primer (5'-CATCCTACCATGTCAAGAGCCAG3') and reverse primer (5'-GCTTGTTAAGGTGGTCTGGTTTAAATT-3'), ${ }^{(25)}$

- $\beta$-Actin forward primer (5'-TCCTATGTGGGTGACGAGGC$\left.3^{\prime}\right)$ and $\beta$-actin reverse primer (5'-CATGGCTGGGGTGTTGAAGG-3'). ${ }^{(15)}$

The qRT-PCR reaction was performed using Brilliant II QPCR master mix (Stratagene, La Jolla, CA) scaled down to a $25 \mu$ per reaction. The reaction followed standard conditions and the melting temperature was $55^{\circ} \mathrm{C}$. qRT-PCR results were expressed as fold change of relative amount of mRNA (User Bulletin of ABI Prism 7700 sequence detection system, 1997)..$^{(23)}$

Total protein extraction. Cells were washed twice with $1 \times$ PBS ( $1 \mathrm{ml}$ in apical compartment and $1 \mathrm{ml}$ in basolateral compartment) and harvested in $1 \mathrm{ml}$ of $1 \times$ ice cold PBS followed by centrifugation at $14,000 \mathrm{rpm}$ for $3-5 \mathrm{~min}$ at $4^{\circ} \mathrm{C}$. Contents of 2 to 3 wells were combined and centrifuged to increase the cell number in each microcentrifuge tube. After discarding the PBS supernatant, cell pellets were lysed on ice for $20 \mathrm{~min}$ using 50-60 $\mu \mathrm{l}$ of lysis buffer consisting of $1 \%$ Nonidet P-40 (NP-40), $0.5 \%$ sodium deoxycholate, $150 \mathrm{mM} \mathrm{NaCl}, 20 \mathrm{mM}$ Tris- $\mathrm{HCl} \mathrm{pH}$ 8.0, 5\% SDS, $10 \mathrm{mM}$ DTT, and $1 \mathrm{mM}$ PMSF. During the lysis process, cells were vigorously shaken every $5 \mathrm{~min}$ for complete lysis. Cells were then centrifuged at $14,000 \mathrm{rpm}$ for $10 \mathrm{~min}$ at $4^{\circ} \mathrm{C}$ to remove cell debris. Protein concentration was measured using the BCA protein assay kit according to the manufacturer's protocol (Pierce, Rockford, IL). Cell lysates were denatured and stabilized by adding sample solvent (final concentration after adding together was $10 \%$ glycerol, $0.1 \%$ bromophenol blue, $2 \%$ SDS, $50 \mathrm{mM}$ Tris-Cl pH 6.8, and $10 \mathrm{mM}$ DTT) and placed in a boiling water bath for $5 \mathrm{~min}$. Samples were then directly used for SDS-PAGE or stored at $-80^{\circ} \mathrm{C}$.

Western blot analysis. For Western blot analysis, equal amounts of protein-containing lysates $(35 \mu \mathrm{g})$ were loaded onto $8 \%$ SDS-PAGE mini-gels and separated by electrophoresing with $35 \mathrm{~mA} /$ gel constant current for $1 \mathrm{~h}$. The separated proteins were then electro-transferred at $100 \mathrm{~V}$ to PVDF membranes (BioRad, 


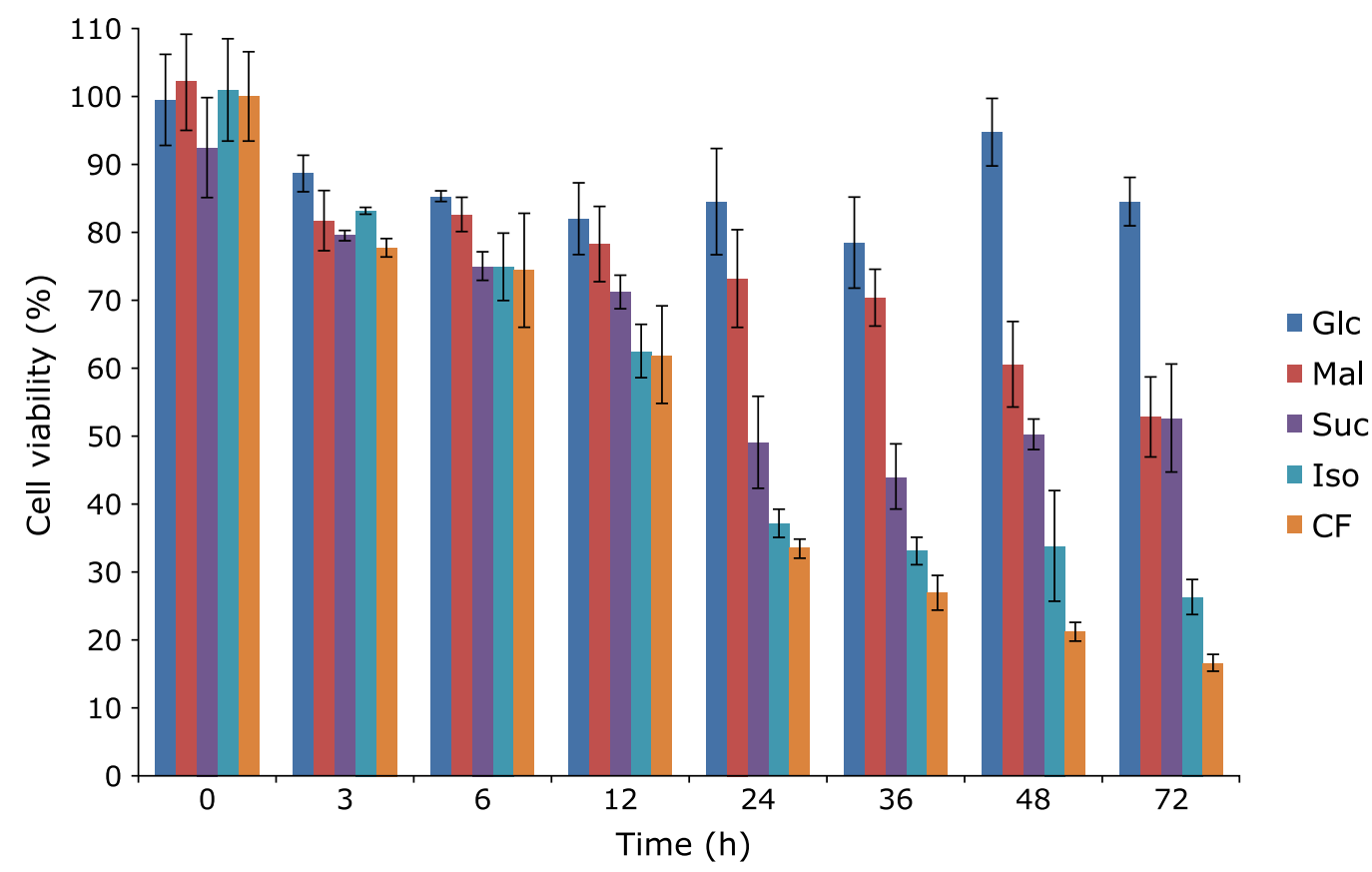

Fig. 1. Viability of Caco-2/TC7 cells at different times after being fed with carbohydrate-free media (CF) or the same media supplemented with $12.5 \mathrm{mM}$ sucrose (Suc), $25 \mathrm{mM}$ fructose (Fru), $25 \mathrm{mM}$ glucose (Glc), $12.5 \mathrm{mM}$ maltose (Mal), or $12.5 \mathrm{mM}$ isomaltose (Iso).

Hercules, CA) at room temperature with ice in the transfer cassette for $1.5 \mathrm{~h}$. The membranes were blocked with phosphate buffered saline containing $5 \%$ skim milk (BioRad, Hercules, CA) and $0.1 \%$ Tween 20 (BioRad, Hercules, CA) at room temperature for $1-2 \mathrm{~h}$ and then allowed to react with $1 / 1500$ dilution of mouse anti-SI antibodies (B. Nichols, Baylor College of Medicine) (mixed with equal volume of HSI 1/691/79, HIS 3/190, and HIS 3/42/1/2; Quezada-Calvillo et al., 2007). ${ }^{(8)}$ After incubation with horseradish-peroxidase-conjugated secondary antibody (1/2000 dilution, anti-mouse and anti-goat, from Santa Cruz Biotechnology, Santa Cruz, CA; anti-rabbit from Amersham, GE Healthcare Biosciences, Piscataway, NJ), proteins were visualized using enhanced chemiluminescence (ECL) (Pierce, Rockford, IL or Amersham of GE Healthcare Biosciences, Piscataway, NJ) followed by exposure to Amersham hyperfilm.

Western blot signals used for protein quantification were measured using ImageStudioLite software (LI-COR Biosciences, Lincoln, NE). Band intensities of SI with different treatments and at different incubation times were measured and quantified based on corresponding $\beta$-actin band intensity (SI band intensity/ $\beta$-actin band intensity).

\section{Results}

Caco-2/TC7 cell model. For carbohydrate digestion and absorption, the viability of Caco-2/TC7 cells on the different test carbohydrates was first investigated. Cells maintained a normal viability for two days when feeding was $\geq 12.5 \mathrm{mM}$ glucose. When different carbohydrates were tested (equivalent with $12.5 \mathrm{mM}$ glucose), cells fed by the glucose had a higher viability than those fed by disaccharides of maltose, sucrose and isomaltose. Among the disaccharides, maltose had the highest viability (Fig. 1). Although the viability measured by MTS showed lower values when disaccharides were the energy source, there was not a significant difference in number of viable cells and the total protein content (data not shown), indicating that cells cultured under these conditions maintained cell viability within the time duration of 2 days. Thus, the Caco2/TC7 line was determined appropriate as a model system to study the digestion and absorption of the test carbohydrates.

Carbohydrate digestion and absorption. Caco-2 cells absorbed and transported glucose, as well as fructose (not shown), to reach an apparent equilibrium between the apical and basolateral regions of the transwells (Fig. 2). After glucose concentration equilibrated, a gradual decrease in both apical and basolateral regions was likely due to sugar utilization by the cells. Maltose was digested as evidenced by a gradual increase in glucose in both the apical and basolateral regions. Therefore, SI functioned to hydrolyze maltose to glucose which was transported through the cell monolayer. Perhaps of note, a repeatable initial lag of $\sim 2.5 \mathrm{~h}$ of appearance of glucose in both apical and basolateral sides was observed that could coincide with a recognition of the substrate and maturation of SI for its digestion.

\section{Gene expression affected by carbohydrate treatment.}

Following treatment of the Caco-2 cells with the different carbohydrates, expression of SI, SGLT1, GLUT5, and GLUT2 was measured at different time points using qRT-PCR. Expression levels were positive in all cases compared to that of carbohydratefree media (Fig. 3). Notably, SI expression incrementally increased over $24 \mathrm{~h}$ after exposure to maltose, compared to glucose which did not over the same period; and at $48 \mathrm{~h}$ had opposite effects of decrease in the former increase in the latter. This suggests that the two sugar molecules were sensed differently by the enterocytes and, in the case of maltose, triggered SI expression perhaps related to the need for it to be digested. The $\alpha-1,6$ linked isomaltose, which was only digested at a very low rate as evidenced by cell viability (Fig. 1) and digestion/absorption (not shown) data; showed a similar, though less pronounced, trend as maltose.

For the transporters, mRNA levels of SGLT1 went through a cycling pattern of an initial rise in expression followed by a reduction, and then again a rise. A difference was seen between glucose and maltose, as well as with isomaltose and fructose, with the latter producing a more delayed inflection point; perhaps due to 

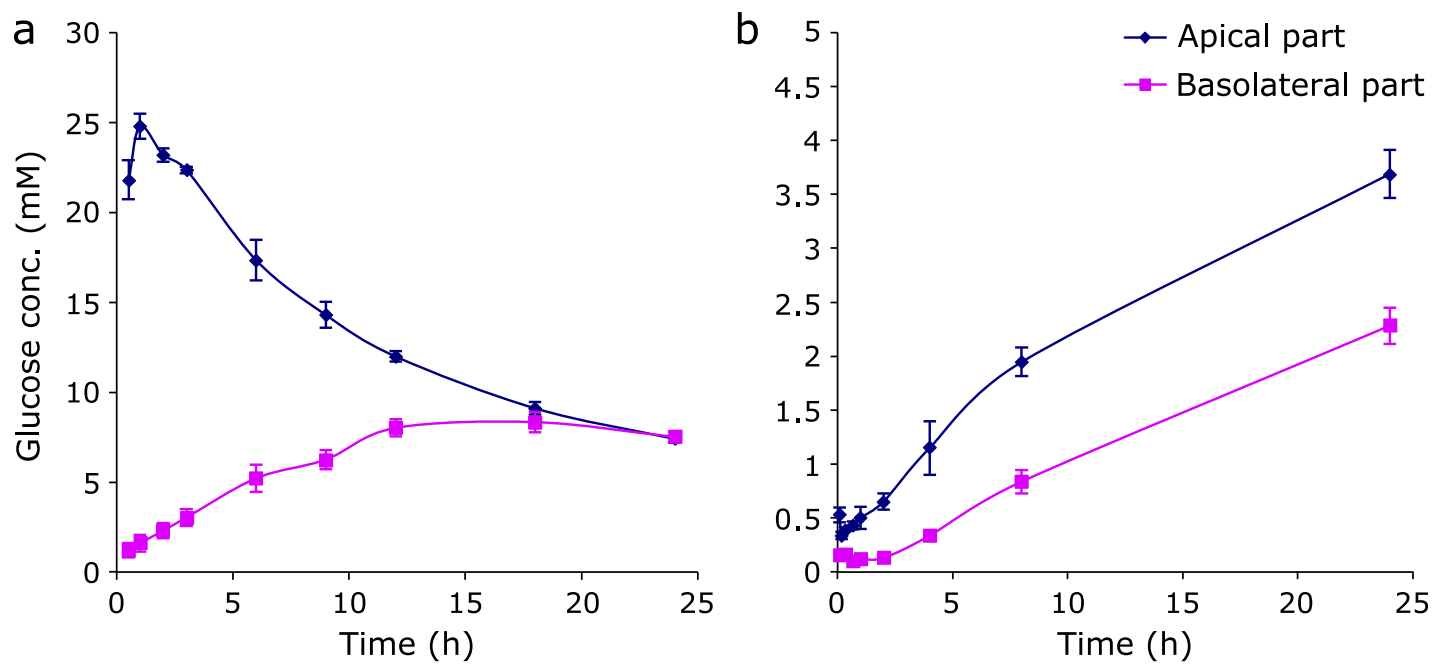

Fig. 2. Digestion (loss in the apical compartment) and absorption (gain in the basolateral compartment) through the Caco-2/TC7 monolayer of the monosaccharide glucose (a), compared to the disaccharide maltose (Glc $\alpha-1,4 \mathrm{Glc}$ ) (b).
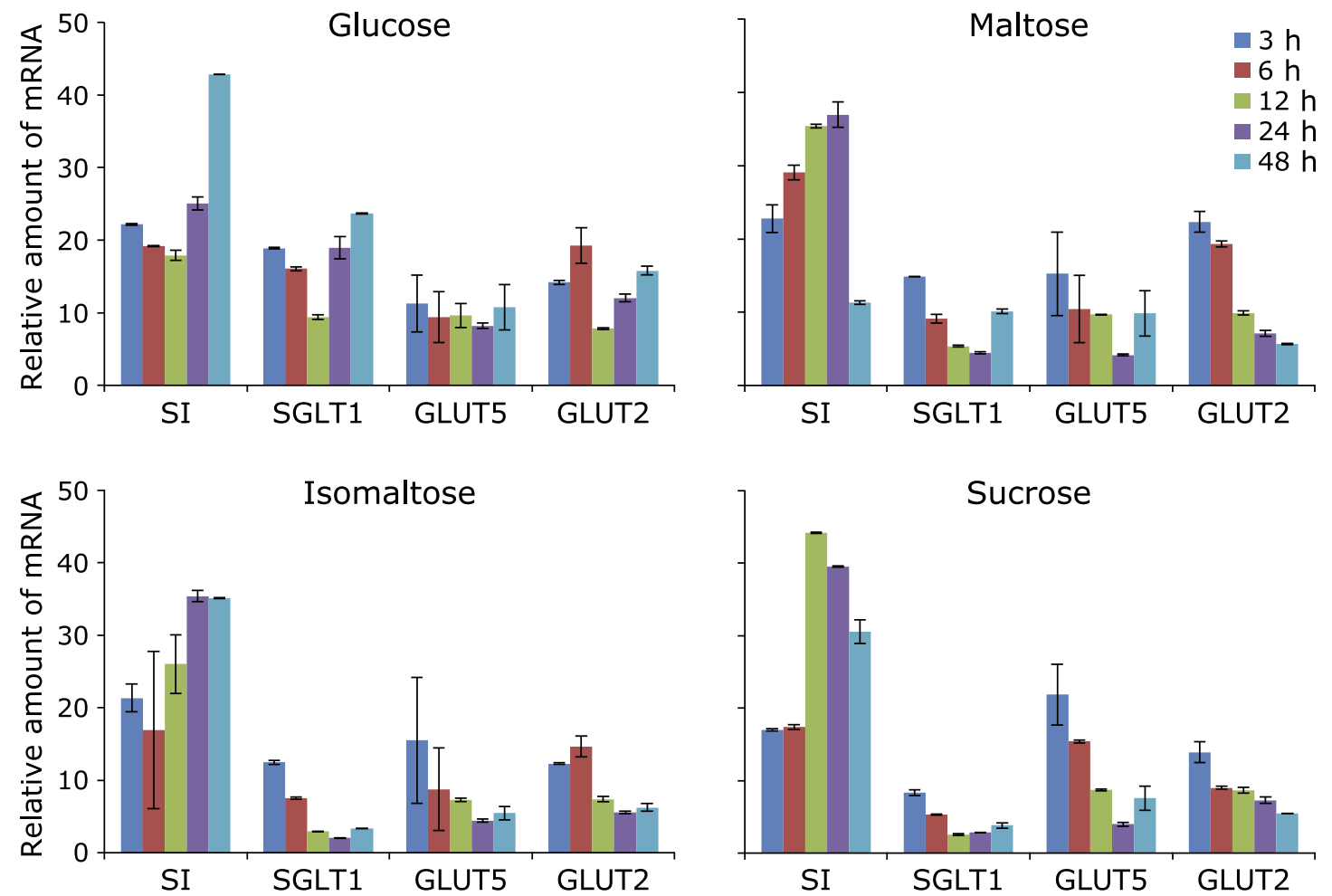

Fig. 3. $\mathrm{qRT}-\mathrm{PCR}$ results of gene transcription of different carbohydrate transporters and SI. The data are presented as fold change of mRNA levels over the lowest mRNA expression of cells treated in carbohydrate-free media. Results represent the mean \pm SEM of at least three wells of treated Caco-2 cells.

lower glucose concentrations. GLUT5 gene expression was initially most affected by fructose, agreeing with its function in fructose transport. For GLUT2, which is mainly responsible for transporting the monosaccharide out to the basal-lateral side, all showed similar initial mRNA levels, and glucose showing a cycling pattern while the others a reduction in levels over time.

\section{SI change in molecular weight induced by maltose.}

Western blotting of SI in cells treated with the different carbohydrates showed that maltose alone caused a shift to higher molecular weight at $12 \mathrm{~h}$ and with a subsequent lowering of molecular weight at 24 h (Fig. 4). Different concentrations of maltose were also used in the culture media, and a level of $12.5 \mathrm{mM}$ was found to be the minimum level of maltose for the induction of the high molecular band of SI (not shown). This higher molecular band of SI appeared over the $250 \mathrm{kDa}$ protein marker, compared to the lower SI molecular weight of $245 \mathrm{kDa}$ suggesting post-translational modification. Immunoprecipitation with MALDI-TOF analysis of tryptic peptides verified that the higher molecular weight variant was SI (not shown).

Levels of SI in Western blots were notably higher with maltose 


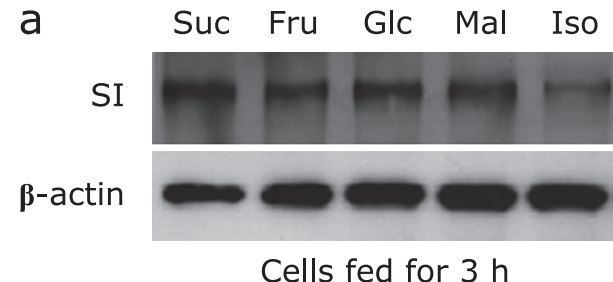

Cells fed for $3 \mathrm{~h}$

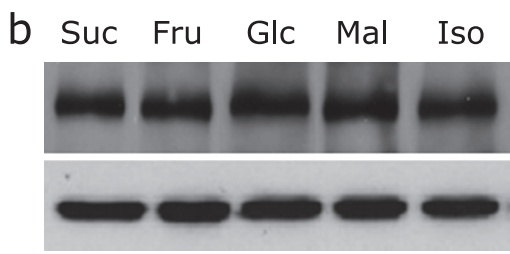

Cells fed for $6 \mathrm{~h}$
C

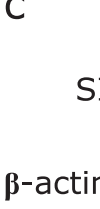

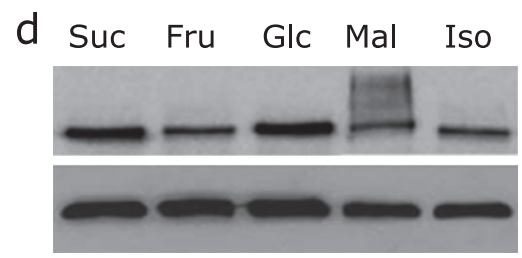

Cells fed for $24 \mathrm{~h}$

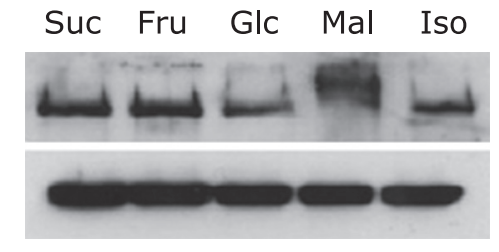

Cells fed for $12 \mathrm{~h}$ different sugars for $12 \mathrm{~h}$. Only maltose showed a shift it the Fig. 4. Western blots of the sucrase isomaltase (SI) enzyme complex after feeding with different sugars
band to a higher molecular weight species, which may be the active form of SI that can digest maltose.

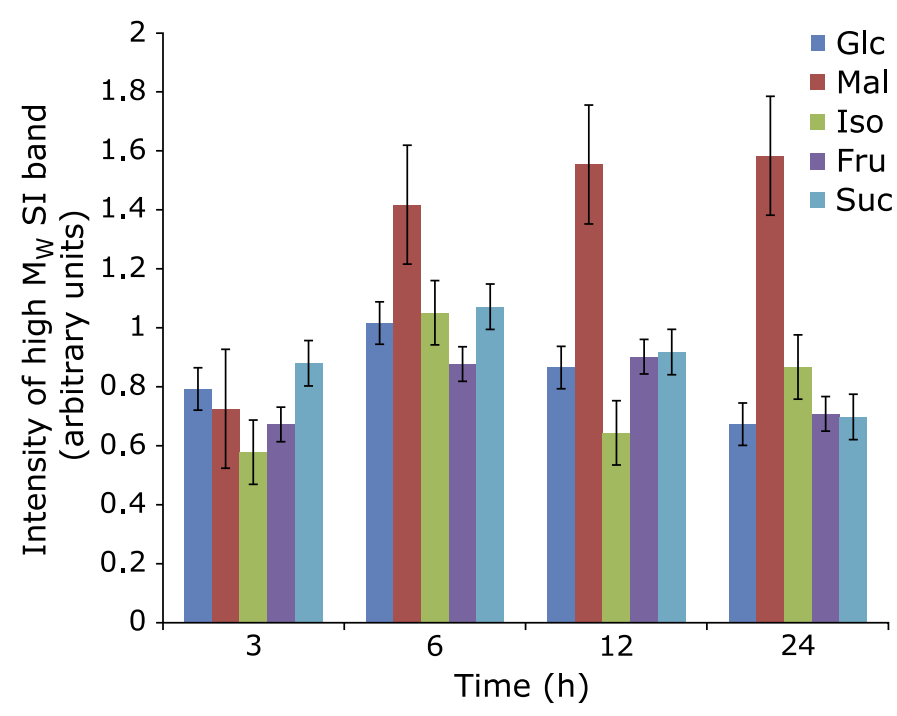

Fig. 5. Intensity of the high molecular weight SI band in Western blots reveals a higher protein expression level in Caco-2 cells treated with maltose compared to other sugars (mean $\pm \mathrm{SD}, n=3$ ).

treatment at 6,12 , and $24 \mathrm{~h}$, than were SI levels for other treatments (Fig. 5). This supported qRT-PCR results where SI expression increased over time with maltose treatment.

\section{Discussion}

While small intestinal enterocyte monosaccharide (sugar) sensing has been known to alter metabolic events within the cell, including SI gene expression, and trigger gut hormone responses with systemic consequences, ${ }^{(14,15,24)}$ sensing of $\alpha$-amylase starch degradation products (maltose or other maltooligosaccharides) by gut enterocytes with effect on SI has not been reported. In appetite studies, maltose sensing was recently reported at the site of the sweet taste receptor T1R2 and T1R3 subunits, ${ }^{(25,26)}$ however was not related to SI processing or maltooligosaccharide digestion. In a way, the existence of an enterocyte sensing mechanism for starch degradation products would not be surprising given the importance of dietary glucose generation to the body. Dietaryderived glucose, versus that from glycogenolysis or gluconeogenesis, supplies a critical portion of glucose for metabolic processes. In an era of excess caloric intake in industrialized countries, and even in urbanized areas of developing countries, the body remains wired to efficiently digest starch and take up the glucose product.

Of the small intestine enterocyte $\alpha$-glucosidases, SI and MGAM, Caco-2 cells only express SI. However, SI includes the activities of MGAM and is, thus, a good representative complex for human $\alpha$-glucosidase activity. ${ }^{(27)} \mathrm{SI}$ is a highly glycosylated protein with $\mathrm{N}$ - and $\mathrm{O}$-glycosylation sites that are added during cotranslational and post-translational processing, as is similar to that of other glycoproteins, ${ }^{(28)}$ before the final insertion of the enzyme in the microvillar membrane. ${ }^{(29)} \mathrm{N}$ - and O-glycosylation of SI are essential modifications that are associated with folding and intracellular trafficking. ${ }^{(30)}$ SI is sorted to the apical membrane via O-linked glycans that mediate its association with lipid rafts or detergent-resistant membranes which is associated with increased SI activity. ${ }^{(31)}$

In the present study, only maltose treatment induced synthesis of a higher Mw SI protein band and MALDI-TOF and MS/MS analyses verified it to be SI. Expression level was higher for the new species of SI in cells treated with maltose compared to the other treatments. We speculate that this coincides with the final O-glycosylation step for trafficking SI to the lipid raft for subsequent maltose digestion. Thus, maltose, in contrast to other sugars tested, may act as a signal molecule to trigger SI processing and trafficking to the apical membrane.

The indication of maltose sensing in the current study has implications as another possible control point of starch digestion and glucogenesis. The data suggests that maltose may positively affect the post-translational processing of SI to mobilize and activate the enzyme at the enterocyte apical surface.

\section{Conflict of Interest}

No potential conflicts of interest were disclosed. 


\section{References}

1 Aston LM. Glycemic index and metabolic disease risk. Proc Nutr Soc 2006; 65: $125-134$.

2 Brand-Miller JC. Glycemic load and chronic disease. Nutr Rev 2003; 61: S49-S55.

3 Gropper SS, Smith JL, Groff JL. The digestive system: Mechanism for nourishing the body. In: Advanced Nutrition and Human Metabolism (4th ed). California: Thomson/Wadsworth, 2004; 24-53.

4 Lebenthal E. Role of salivary amylase in gastric and intestinal digestion of starch. Dig Dis Sci 1987; 32: 1155-1157.

5 Semenza G, Auricchio S, Mantei N, et al. The metabolic basis of inherited disease (8th ed). New York: McGraw-Hill, 2001; 1623-1650.

6 Conklin KA, Yamashiro KM, Gray GM. Human intestinal sucrase-isomaltase. Identification of free sucrase and isomaltase and cleavage of the hybrid into active distinct subunits. J Biol Chem 1975; 250: 5735-5741.

7 Gray GM, Lally BC, Conklin KA. Action of intestinal sucrase-isomaltase and its free monomers on an $\alpha$-Limit Dextrin. J Biol Chem 1979; 254: 60386043.

8 Quezada-Calvillo R, Robayo-Torres CC, Ao Z, et al. Luminal substrate "brake" on mucosal maltase-glucoamylase activity regulates total rate of starch digestion to glucose. J Pediatr Gastroenterol Nutr 2007; 45: 32-43.

9 Heymann H, Günther S. Calculation of subsite affinities of human small intestinal glucoamylase-maltase. Biol Chem Hoppe Seyler 1994; 375: 451455.

10 Heymann H, Breitmeier D, Günther S. Human small intestinal sucraseisomaltase: different binding patterns for malto- and isomaltooligosaccharides. Biol Chem Hoppe Seyler 1995; 376: 249-253.

11 Robayo-Torres CC, Quezada-Calvillo R, Nichols BL. Disaccharide digestion: clinical and molecular aspects. Clin Gastroenterol Hepatol 2006; 4: 276-287.

12 Levin R. Digestion and absorption of carbohydrates-from molecules and membranes to humans. Am J Clin Nutr 1994; 59: 690S-698S.

13 Helliwell PA, Richardson M, Affleck J, Kellett GL. Stimulation of fructose transport across the intestinal brush-border membrane by PMA is mediated by GLUT2 and dynamically regulated by protein kinase C. Biochem J 2000; 350: 149-154.

14 Kishi K, Tanaka T, Igawa M, Takase S, Goda T. Sucrase-isomaltase and hexose transporter gene expressions are coordinately enhanced by dietary fructose in rat jejunum. $J$ Nutr 1999; 129: 953-956.

15 Le Gall M, Tobin V, Stolarczyk E, Dalet V, Leturque A, Brot-Laroche E. Sugar sensing by enterocytes combines polarity, membrane bound detectors and sugar metabolism. J Cell Physiol 2007; 213: 834-843.

16 Turco L, Catone T, Caloni F, Di Consiglio E, Testai E, Stammati A. Caco-2/ TC7 cell line characterization for intestinal absorption: how reliable is this in vitro model for the prediction of the oral dose fraction absorbed in human? Toxicol In Vitro 2011; 25: 13-20.

17 Hidalgo IJ, Raub TJ, Borchardt RT. Characterization of the human colon carcinoma cell line (Caco-2) as a model system for intestinal epithelial perme- ability. Gastroenterology 1989; 96: 736-749.

18 Sambuy Y, De Angelis I, Ranaldi G, Scarino ML, Stammati A, Zucco F. The Caco-2 cells line as a model of the intestinal barrier: influence of cell and culture-related factors on Caco-2 cell functional characteristics. Cell Biol Toxicol 2005; 21 : 1-26.

19 Mahraoui L, Rodolosse A, Barbat A, et al. Presence and differential expression of SGLT1, GLUT1, GLUT2, GLUT3, and GLUT5 hexose-transporter mRNAs in Caco-2 cell clones in relation to cell growth and glucose consumption. Biochem J 1994; 298: 629-633.

20 Barltrop JA, Owen TC, Cory AH, Cory JG. 5-(3-carboxymethoxyphenyl)-2(4,5-dimethylthiazolyl)-3-(4-sulfophenyl)tetrazolium, inner salt (MTS) and related analogs of 3-(4,5-dimethylthiazolyl)-2,5-diphenyltetrazolium bromide (MTT) reducing to purple water-soluble formazans as cell-viability indicators. Bioorg Med Chem Lett 1991; 1: 611-614.

21 Guillemain G, Munoz-Alonso MJ, Cassany A, et al. Karyopherin alpha2: A control step of glucose- sensitive gene expression in hepatic cells. Biochem $J$ 2002; 364: 201-209.

22 Faller G, Dimmler A, Rau T, et al. Evidence for acid-induced loss of Cdx2 expression in duodenal gastric metaplasia. J Pathol 2004; 203: 904-908.

23 Schmittgen TD, Livak KJ. Analyzing real-time PCR data by the comparative $\mathrm{C}_{\mathrm{T}}$ method. Nature Protocols 2008; 3: 1101-1108.

24 Margolskee RF, Dyer J, Kokrashvili Z, et al. T1R3 and gustducin in gut sense sugars to regulate expression of $\mathrm{Na}^{+}$-glucose cotransporter 1. Proc Natl Acad Sci U S A 2007; 104: 15075-15080.

25 Sclafani A. Sweet taste signaling in the gut. Proc Natl Acad Sci U S A 2007; 104: $14887-14888$.

26 Treesukosol Y, Blonde GD, Spector AC. T1R2 and T1R3 subunits are individually unnecessary for normal affective licking response to Polycose: implication for saccharide taste receptors in mice. Am J Physiol Regul Integr Comp Physiol 2009; 296: R855-R865.

27 Lin AH, Lin BH, Nichols BL, et al. Starch source influences dietary glucose generation at the mucosal $\alpha$-glucosidase level. J Biol Chem 2012; 287: 36917-36921.

28 Sehachter H, Roseman S. Mammalian glycosyltransferases: their role in the synthesis and function of complex carbohydrates and glycolipids. In: Lennarz WJ, ed. The Biochemistry of Glycoproteins and Proteoglycans. New York: Plenum Publishing Corp., 1980; 85-160.

29 Hunziker W, Spiess M, Semenza G, Lodish H. The sucrase-isomaltase complex: primary structure, membrane-orientation, and evolution of a stalked, intrinsic brush border protein. Cell 1986; 46: 227-234.

30 Naim HY, Sterchi EE, Lentze MJ. Biosynthesis of the human sucraseisomaltase complex. Differential O-glycosylation of the sucrase subunit correlates with its position within the enzyme complex. J Biol Chem 1988; 263: 7242-7253.

31 Wetzel G, Heine M, Rohwedder A, Naim HY. Impact of glycosylation and detergent-resistant membranes on the function of intestinal sucrase-isomaltase. Biol Chem 2009; 390: 545-549. 